\title{
AVALIAÇÃO FÍSICO-QUÍMICA DE UVA MINIMAMENTE PROCESSADA ADICIONADA DE ÁCIDO ASCÓRBIDO E DE ÁCIDO CÍTRICO
}

\author{
Kamila Ferreira Chaves \\ Graduanda em Ciência e Tecnologia de Alimentos / IF Sudeste - campus Rio Pomba / MG \\ chaves_kamila@yahoo.com.br \\ Welliton Fagner da Cruz \\ Mestrando em Ciência e Tecnologia de Alimentos / UFV / MG \\ wellitondacruz@yahoo.com.br
}

\section{Aurélia Dornelas de Oliveira Martins}

Doutora em Ciência e Tecnologia de Alimentos / UFV / MG

Professora do Bacharel em Ciência e Tecnologia de Alimentos / IF Sudeste - campus Rio Pomba / MG

aureliadom@yahoo.com.br

\section{Vanessa Riani Olmi Silva}

Doutora em Ciência e Tecnologia de Alimentos / UFV / MG

Coordenadora do Bacharel em Ciência e Tecnologia de Alimentos / IF Sudeste - campus Rio Pomba / MG

vanessarolmi@yahoo.com.br

\section{Maurício Henriques Louzada Silva}

Doutor em Ciência e Tecnologia de Alimentos / UFV / MG

Professor do Bacharel em Ciência e Tecnologia de Alimentos / IF Sudeste - campus Rio Pomba / MG

mlouzadacefet@yahoo.com.br

\section{Eliane Maurício Furtado Martins}

Mestre em Microbiologia Agrícola / UFV / MG

Professora do Bacharel em Ciência e Tecnologia de Alimentos / IF Sudeste - campus Rio Pomba / MG

eliane.furtado@ifsudestemg.edu.br

\section{RESUMO}

Os principais problemas de conservação pós-colheita em uvas de mesa são a ocorrência de danos mecânicos, podridões, escurecimento das bagas e degrana, o que compromete a aceitação pelos consumidores, muitos dos quais estão atentos aos benefícios de uma vida saudável, que incluem o consumo de uma variedade de frutas na dieta. O objetivo deste trabalho foi avaliar as características físico-químicas da uva cultivar "Rubi" minimamente processada adicionada de antioxidantes. Após o processamento, foi realizada a adição dos ácidos cítrico e ascórbico, ambos na concentração de $2 \%$, e em seguida as uvas foram embaladas e armazenadas a temperatura de 5 e $10{ }^{\circ} \mathrm{C}$ para posterior realização das análises físico-químicas após 24,48 , 72 e 96 horas. A adição dos ácidos ascórbico e cítrico influenciou as variáveis sólidos solúveis, acidez titulável e umidade. Já a perda de massa e $\mathrm{pH}$ foram afetados pela temperatura de estocagem, enquanto o $\mathrm{pH}$, a atividade de água, a perda de massa e o conteúdo de sólidos solúveis foram interferidos pelo tempo de armazenamento. Além disso, a uva apresentou variação na perda de massa em relação à temperatura de armazenamento, sendo menor a $5{ }^{\circ} \mathrm{C}$. Podemos concluir que a aplicação de antioxidantes em uvas cv.'Rubi' minimamente processadas afetou suas características físico-químicas e a temperatura ideal de armazenamento é a $5{ }^{\circ} \mathrm{C}$ por promover menor perda de massa.

Palavras-chave: Processamento mínimo de frutas; antioxidantes; Vitis vinifera L.

\begin{abstract}
Os main problems in post-harvest table grapes are the occurrence of mechanical damage, rot, dark berries and thresh, which compromises the acceptance by consumers, many of whom are aware of the benefits of a healthy lifestyle which include consumption of a variety of fruits in the diet. The objective of this study was
\end{abstract}


to evaluate the physical and chemical characteristics of the grape cultivar "Ruby" minimally processed with added antioxidants. After processing, was conducted the addition of ascorbic and citric acids, both at a concentration of $2 \%$, and then the grapes were packed and stored at a temperature of 5 and $10^{\circ} \mathrm{C}$ to perform the physical and chemical analysis after 24, 48, 72 and 96 hours. The addition of ascorbic and citric acids influence variables soluble solids, acidity and humidity. Since the contents of mass loss and $\mathrm{pH}$ were affected by storage temperature while the $\mathrm{pH}$, water activity, weight loss and soluble solids were interfered with by the storage time. Moreover, the grape showed a variation in mass loss in relation to storage temperature, being below of the $5^{\circ} \mathrm{C}$. We can conclude that the application of antioxidants in grapes cv. 'Rubi' minimally processed affected their physical and chemical characteristics and the ideal storage temperature is $5^{\circ} \mathrm{C}$ lower for promoting weight loss.

Keywords: Minimal processing of fruit; antioxidants; Vitis vinifera L.

\section{INTRODUÇÃO}

Nos últimos anos, a indústria de alimentos tem passado por constantes mudanças para se adaptar às crescentes exigências dos consumidores, que demandam cada vez mais por produtos com validade comercial prolongada, além da manutenção de suas características sensoriais e nutricionais (HEIFFIG; AGUILA; KLUGE, 2006). O processamento mínimo tem por objetivo suprir essas exigências, disponibilizando produtos frescos que são comercializados limpos, convenientes, e que podem ser preparados e consumidos em menor tempo (CHITARRA, 2001). Além disso, torna possível a agregação de valor aos produtos, o maior aproveitamento da produção, a redução das perdas pós-colheita e a maior eficiência no manejo de resíduos (MATTIUZ et al., 2004).

Barcelos e Ferrua (2003), afirmam que a eliminação dos desperdícios de frutas e hortaliças, bem como o abastecimento equilibrado de alimentos durante todo o ano, só seria possível mediante o estímulo ao processamento do alimento. Entretanto, quando se trata do segmento de frutas, pode-se observar um aumento na procura de frutas in natura em comparação às frutas processadas, apesar da dificuldade de conservação (GOMES et al, 2007), pois para se obter êxito na comercialização de frutas in natura, estes devem apresentar boa qualidade para o consumidor e menor índice de perdas pós-colheita para o produtor.

Devido à sua fragilidade, as uvas são muito perecíveis, sendo difícil evitar suas deteriorações (ALBERTINI; MIGUEL; SPOTO, 2009). De acordo com Freitas et al. (2008), as perdas pós-colheita de uvas têm sido estimadas em cerca de $27 \%$ da produção total, sendo estas principalmente de origem mecânica e fisiológica e por infecção microbiana, caracterizadas pela perda de peso, escurecimento da ráquis, amolecimento das bagas e desenvolvimento de fungos causadores de podridões (MATTIUZ et al. 2004).

O processamento mínimo de uvas é uma alternativa interessante, pois permite a valorização das bagas de boa qualidade, provenientes de cachos não adequados à comercialização devido a problemas de degrana ou de bagas defeituosas (MATTIUZ et al., 2009). Porém, as frutas minimamente processadas possuem menor vida de prateleira quando comparadas aos íntegros, pois sofrem uma série de danos oxidativos devido às lesões ocorridas durante o período de preparo (descascamento e corte), o que acelera o metabolismo devido ao rompimento celular que promove o contato entre enzimas e seus substratos, além de proporcionar o escurecimento da fruta (JACOMINO et al., 2004). No entanto, existem algumas maneiras de controlar esses problemas por meio da adição de agentes que evitam o escurecimento enzimático (ácido cítrico e ácido ascórbico) e a perda de peso (cloreto de cálcio) (LIMA et al., 2005).

A literatura reporta vários trabalhos sobre processamento mínimo de frutas (TEIXEIRA et al., 2001; CARAVALHO e LIMA, 2002; MATTIUZ et al., 2004; MELO e VILAS BOAS, 2006; JUNIOR, 2007; CENCI, 2008), porém não há estudos que avalie simultaneamente a qualidade físico-química de uvas minimamente processadas, em relação ao efeito da adição de agentes antioxidantes em diferentes tempos e temperaturas de armazenamento. Portanto, verificou-se a necessidade de estudos mais aprofundados sobre os efeitos da adição de agentes antioxidantes na qualidade físico-química de uvas minimamente processadas armazenadas em tempos e temperaturas diferentes. 


\section{MATERIAL E MÉTODOS}

As uvas, cultivar "Rubi", provenientes do comercio local de Rio Pomba - MG, foram processadas na Unidade de Processamento de Frutas e Hortaliças do IF-Sudeste de Minas/Campus Rio Pomba, à temperatura ambiente $\left( \pm 27^{\circ} \mathrm{C}\right)$, sendo inicialmente selecionadas e pré-lavadas conforme procedimentos exigidos pela Boas Práticas de Fabricação, para eliminação das sujidades orindas do campo. Em seguida, os frutos foram sanitizados com água clorada $150 \mathrm{mg} \cdot \mathrm{L}^{-1}$ a $5{ }^{\circ} \mathrm{C}$, para redução do metabolismo do fruto, e enxaguados com água clorada $5 \mathrm{mg} \cdot \mathrm{L}^{-1}$ a $5{ }^{\circ} \mathrm{C}$, com a finalidade de remover o excesso de cloro na superfície dos frutos.

Posteriormente, realizou-se o corte (manual) longitudinal das bagas com auxílio de facas de aço inoxidável (tratamento controle) e adicionaram-se os agentes antioxidantes (ácido ascórbico e ácido cítrico) por meio da imersão de diferentes lotes das frutas minimamente processadas em solução aquosa contendo 2 $\%$ de cada ácido, sendo estas drenadas por 2 minutos. O produto foi então embalado em bandejas de isopor (contendo aproximadamente 80 metades do fruto) recobertas com filme de cloreto de polivinila (PVC) e armazenados sob temperatura de refrigeração $\left(5\right.$ e $\left.10^{\circ} \mathrm{C}\right)$ para estudo de vida de prateleira nos tempos 0,24 , 48,72 e 96 horas após o processamento.

A fim de verificar as possíveis alterações na qualidade físico-química das uvas minimamente processadas adicionadas de agentes antioxidantes, foram realizadas análises de perda de massa $(\% \mathrm{~m} / \mathrm{dia})$ através de pesagem em balança semi-analítica, com os resultados expressos em porcentagem, considerandose a diferença entre o peso inicial da amostra e aquele obtido a cada intervalo de tempo de amostragem, $\mathrm{pH}$, acidez titulável (g ácido tartárico/100 g), sólidos solúveis totais ( ${ }^{\circ}$ Brix), cinzas $(\% \mathrm{~m} / \mathrm{m})$, umidade $(\% \mathrm{~m} / \mathrm{m})$ e atividade de água de acordo com as metodologias propostas pelo Instituto Adolfo Lutz (ZENEBON et al., 2008).

Os tratamentos foram dispostos num esquema fatorial $3 \times 5 \times 2$, instalado no delineamento inteiramente casualizado, com 3 repetições. Tratamentos (ácido ascórbico, ácido cítrico e controle), tempo (0, 24, 48, 72 e 96 horas) e temperatura $\left(5\right.$ e $\left.10{ }^{\circ} \mathrm{C}\right)$ de armazenamento foram os fatores em estudo. Os resultados obtidos foram submetidos à análise de variância (ANOVA) e ao teste de Tukey para a comparação das médias, ao nível de 5 \% de significância, quando necessário analisados por meio do Sisvar (FERREIRA, 2007).

\section{RESULTADOS E DISCUSSÃO}

A tabela 1 mostra os valores obtidos para análise de sólidos solúveis totais (SST), acidez titulável (AT) e umidade, sendo que somente os conteúdos de SST foram interferidos pela temperatura (tabela 2) de estocagem da uva $\left(5^{\circ} \mathrm{C}\right.$ e $\left.10^{\circ} \mathrm{C}\right)$.

Tabela 1: Valores médios das análises físico-químicas para os diferentes tratamentos da uva cv. "Rubi"

\begin{tabular}{cccc}
\hline Tratamento & $\begin{array}{c}\text { Sólidos Solúveis Totais } \\
\left({ }^{\circ} \text { Brix) }\right.\end{array}$ & $\begin{array}{c}\text { Acidez Titulável (\% de ácido } \\
\text { tartárico) }\end{array}$ & Umidade (\%) \\
\hline Controle & $10,0967 \mathrm{a}$ & $0,41267 \mathrm{a}$ & $88,6493 \mathrm{ab}$ \\
Ácido Ascórbico & $9,6167 \mathrm{ab}$ & $0,43567 \mathrm{a}$ & $88,0050 \mathrm{~b}$ \\
Ácido Cítrico & $9,4633 \mathrm{~b}$ & $0,56500 \mathrm{~b}$ & $89,1783 \mathrm{a}$ \\
\hline
\end{tabular}

Médias seguidas de pelo menos uma mesma letra, na mesma coluna, não diferem entre si ao nível de $5 \%$ de probabilidade pelo teste de Tukey.

Houve diferença no conteúdo de SST entre o tratamento com ácido cítrico e o controle, porém o tratamento com ácido ascórbico não se diferiu significativamente do tratamento com ácido cítrico e nem do controle (Tabela 1). A uva tratada com ácido cítrico apresentou um conteúdo de SST menor que o controle, indicando que o tratamento com ácido retarda a degradação da qualidade comestível da uva cv. "Rubi". O conteúdo de sólidos solúveis totais encontrado no presente estudo estão abaixo dos observados por Mattiuz et al. (2004) 16,06 e $22,17^{\circ}$ Brix em duas cultivares de uvas apirênicas (sem semente) minimamente processadas. Entretanto, a acidez total titulável estiveram próximos aos encontrados por estes autores $(0,56 \mathrm{e}$ $0,86 \%$ ). Teixeira et al. (2001) ao avaliarem a possibilidade do uso de mamões do grupo "Formosa" na 
produção de minimamente processados, assim como conhecer as reações deste fruto e as operações de seu preparo, concluíram que não houve efeito significativo dos tratamentos sobre os conteúdos de sólidos solúveis totais ao longo do período de armazenamento, apesar de ter ocorrido perda de umidade, com os frutos apresentando conteúdo médio de $10,93 \pm 0,740{ }^{\circ}$ Brix.

$\mathrm{Na}$ análise da acidez titulável, a uva tratada com ácido cítrico se diferenciou estatisticamente do controle e do tratamento com ácido ascórbico (Tabela 1). A elevada acidez em produtos minimamente processados é benéfica, sob o ponto de vista microbiológico, pois inibe o crescimento de patógenos nocivos à saúde humana, de tal forma que não comprometa a qualidade sensorial do produto (MATTIUZ et al., 2004). Em contrapartida, Teixeira et al. (2001) verificaram em seus estudos com mamões "Formosa" minimamente processados que a acidez titulável total foi menor nos frutos armazenados a temperaturas mais elevadas, possivelmente devido ao metabolismo mais intenso dos mesmos, o que é confirmado pelos dados de concentração de $\mathrm{CO}_{2}$ nas embalagens.

Já na análise de umidade os tratamentos com os ácidos diferiram entre si, porém não diferiram do controle (Tabela 1). Lima et al. (2005), avaliaram a aplicação de agentes antiescurecimento e antimicrobiano, inibidor da perda de peso e filmes plásticos, como polietileno e PVC, no processamento mínimo de mamão e observaram que as embalagens de PVC não promoveram aumento da umidade relativa, uma vez que $100 \%$ das embalagens apresentavam-se sem incidência de fungos visuais, após 5 dias de armazenamento. As variáveis SST e perda de massa foram interferidas pelas diferentes temperaturas de estocagem para todos os tratamentos, como demonstra a tabela 2.

Tabela 2: Conteúdo de sólidos solúveis totais e perda de massa em diferentes temperaturas de armazenamento da uva cv. "Rubi" em todos os tratamentos avaliados.

\begin{tabular}{ccc}
\hline Temperatura $\left({ }^{\circ} \mathbf{C}\right)$ & Sólidos Solúveis Totais $\left({ }^{\circ}\right.$ Brix) & Perda de Massa $(\%)$ \\
\hline 5 & $9,92 \mathrm{a}$ & $0,24 \mathrm{a}$ \\
10 & $9,53 \mathrm{~b}$ & $0,78 \mathrm{~b}$ \\
\hline
\end{tabular}

Médias seguidas de pelo menos uma mesma letra, na mesma coluna, não diferem entre si ao nível de $5 \%$ de probabilidade pelo teste de Tukey.

Na temperatura de $5^{\circ} \mathrm{C}$, a uva minimamente processada apresentou maior conteúdo de SST $(9,92$ ${ }^{\circ}$ Brix), bem como menor perda de massa $(0,24 \%)$. Nossos resultados estão de acordo com Kluge et al. (2002), que consideraram perdas de massa acima de 1,2\% como prejudiciais às características sensoriais de uvas. Sarzi et al. (2002), que avaliaram o efeito do tipo de preparo e da temperatura de armazenamento na conservação de abacaxi 'pérola' minimamente processado, verificaram que os produtos armazenados a $9{ }^{\circ} \mathrm{C}$ foram os que apresentaram maiores perda de massa fresca, enquanto, a $3^{\circ} \mathrm{C}$, as perdas foram menores.

De acordo com Vilas Boas (2000), a perda de massa é um dos fatores limitantes à vida útil dos produtos hortícolas, estando relacionada à perda de água, causa principal da deterioração, que além de resultar em perdas quantitativas, também prejudicam a aparência (murchamento e enrrugamento), a textura e a qualidade nutricional (CARVALHO, 2000).

A taxa de transpiração é influenciada por fatores internos tais como características morfológicas e anatômicas, relação superfície-volume e estádio de maturidade, além de fatores externos e ambientais, como temperatura, umidade relativa, movimento de ar e pressão atmosférica (MATTIUZ et al., 2004; VILAS BOAS, 2000). Os baixos valores encontrados neste trabalho devem-se, provavelmente, aos efeitos conjugados da temperatura de armazenamento, aliada à embalagem e à modificação da atmosfera no seu interior. Este fato, além de propiciar um retardo na atividade respiratória do material, evitou a formação de um grande déficit de pressão de vapor e, conseqüentemente, a perda de água pelo produto (MATTIUZ et al., 2004).

As tabelas 3 e 4 mostram os valores médios obtidos para $\mathrm{pH}$ e perda de massa da uva nos diferentes tratamentos à temperatura de $5^{\circ} \mathrm{C}$ e $10^{\circ} \mathrm{C}$, respectivamente. 
Tabela 3: pH e perda de massa da uva cv. "Rubi" minimamente processada armazenada à temperatura de 5 ${ }^{\circ} \mathrm{C}$

\begin{tabular}{ccc}
\hline Tratamento & $\mathbf{p H}$ & Perda de Massa (\%) \\
\hline Controle & $3,62 \mathrm{a}$ & $0,24 \mathrm{a}$ \\
Ácido Ascórbico & $3,48 \mathrm{~b}$ & $0,01 \mathrm{a}$ \\
Ácido Cítrico & $3,36 \mathrm{~b}$ & $0,48 \mathrm{a}$ \\
\hline
\end{tabular}

Médias seguidas de pelo menos uma mesma letra, na mesma coluna, não diferem entre si ao nível de $5 \%$ de probabilidade pelo teste de Tukey.

Os resultados nos mostram que Houve diferença estatística significativa nos valores de $\mathrm{pH}$ entre o controle e os tratamentos com antioxidante. A adição dos ácidos ascórbico e cítrico resultou em diminuição do $\mathrm{pH}$. Entretanto, a perda de massa não diferiu estisticamente entre os tratamentos à temperatura de $5{ }^{\circ} \mathrm{C}$.

Tabela 4: pH e perda de massa da uva cv. "Rubi" minimamente processada armazenada à temperatura de 10 ${ }^{\circ} \mathrm{C}$

\begin{tabular}{ccc}
\hline Tratamento & $\mathbf{p H}$ & Perda de Massa (\%) \\
\hline Controle & $3,52 \mathrm{a}$ & $0,50 \mathrm{ab}$ \\
Ácido Ascórbico & $4,49 \mathrm{a}$ & $1,67 \mathrm{a}$ \\
Ácido Cítrico & $3,43 \mathrm{a}$ & $0,17 \mathrm{~b}$ \\
\hline
\end{tabular}

Médias seguidas de pelo menos uma mesma letra, na mesma coluna, não diferem entre si ao nível de $5 \%$ de probabilidade pelo teste de Tukey.

Não houve diferença estatística nos valores de $\mathrm{pH}$ entre os diferentes tratamentos. Quanto à perda de massa, foi observado que apenas as uvas tratadas com os ácidos ascórbico e cítrico apresentaram diferença estatística entre si, quando armazenados à temperatura de $10^{\circ} \mathrm{C}$.

Nas figuras 1 e 2 podemos observar o comportamento das variáveis $\mathrm{pH}$ e atividade de água, respectivamente, em uvas minimamente processadas no decorrer do armazenamento a 5 e $10{ }^{\circ} \mathrm{C}$.

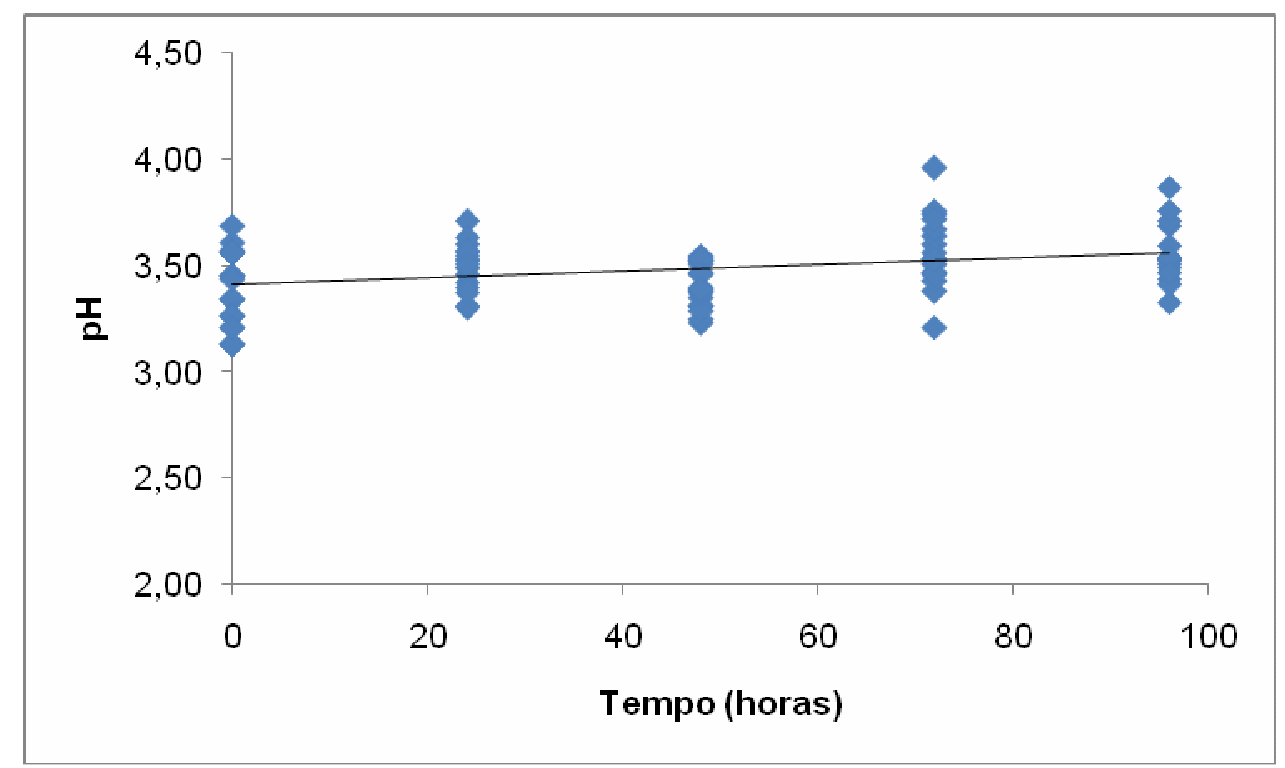

Figura 1: pH da uva cv. "Rubi" nos diferentes tempos de armazenamento.

Os valores médios de $\mathrm{pH}$ encontrados variaram de 3,36 a 3,61 (figura 1), indicando que a uva é uma fruta ácida $(\mathrm{pH}<4,0)$ e estando próximos aos valores obtidos por Albertini et al. (2009). De acordo com a figura 1, observou-se que o $\mathrm{pH}$ da uva aumentou com o tempo de armazenamento. Corroborando com os resultados verificados por Groppo (2007), que percebeu que os valores de pH da laranja "Pêra" 
minimamente processada diferiram significativamente entre os dias de armazenamento quando tratadas com cloreto de cálcio e película de alginato de sódio.

Segundo Brecht et al. (2007), os tratamentos químicos que contém um acidulante, normalmente o ácido cítrico, são usados para prevenir o escurecimento, uma vez que abaixam o $\mathrm{pH}$ inibindo a atividade da polifenoloxidase (PPO). De acordo com Araújo (2011), o abaixamento do pH do tecido reduz a velocidade da reação de escurecimento, sendo o pH ótimo da PPO entre 6,0 e 7,0, e abaixo de 3,0 não há nenhuma atividade enzimática. Como o escurecimento envolve reações oxidativas, outra estratégia para inibí-lo é adição de compostos químicos que funcionam como agentes redutores, como o ácido ascórbico. Dessa forma, ambos são utilizados em tratamentos para manutenção da qualidade de frutas minimamente processadas.

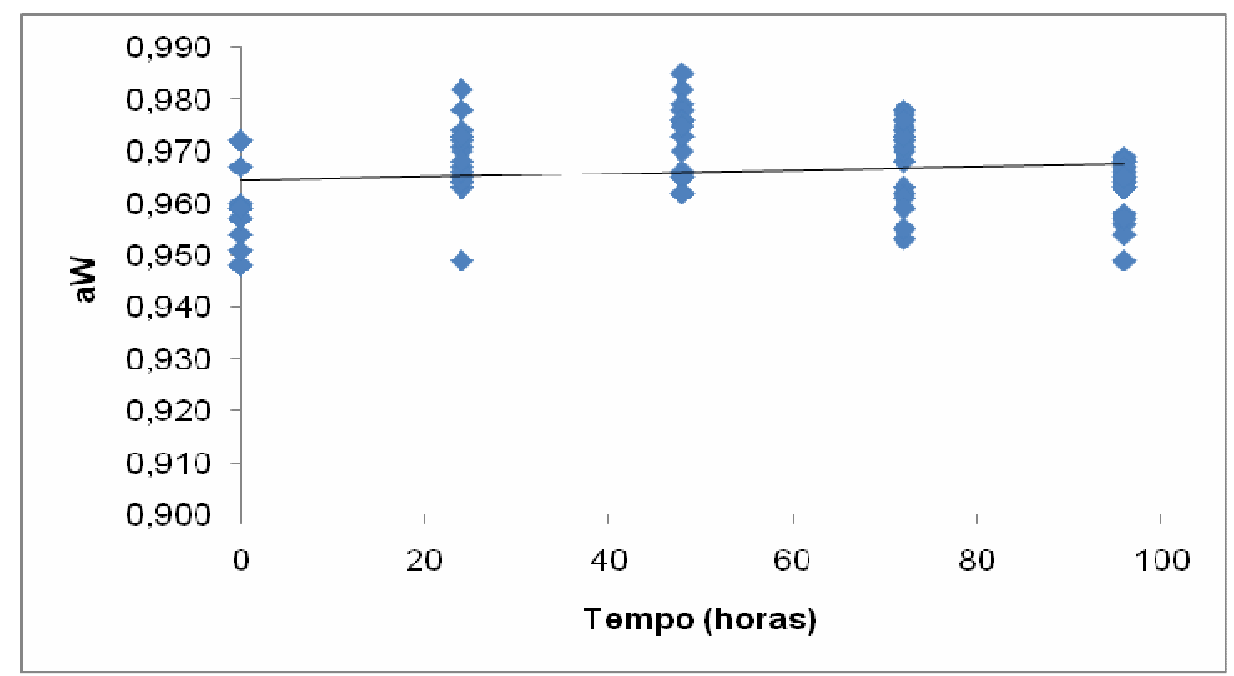

Figura 2: Atividade de água da uva cv. "Rubi" nos diferentes tempos de armazenamento.

Com relação à variação da atividade de água nos diferentes tempos de armazenamento (Figura 2), foi possível observar que houve um aumento significativo $(\mathrm{p}<0,05)$. Nas figuras 3 e 4 podemos observar o comportamento das variáveis sólidos solúveis totais e perda de massa em uvas minimamente processadas no decorrer do armazenamento a 5 e $10^{\circ} \mathrm{C}$.

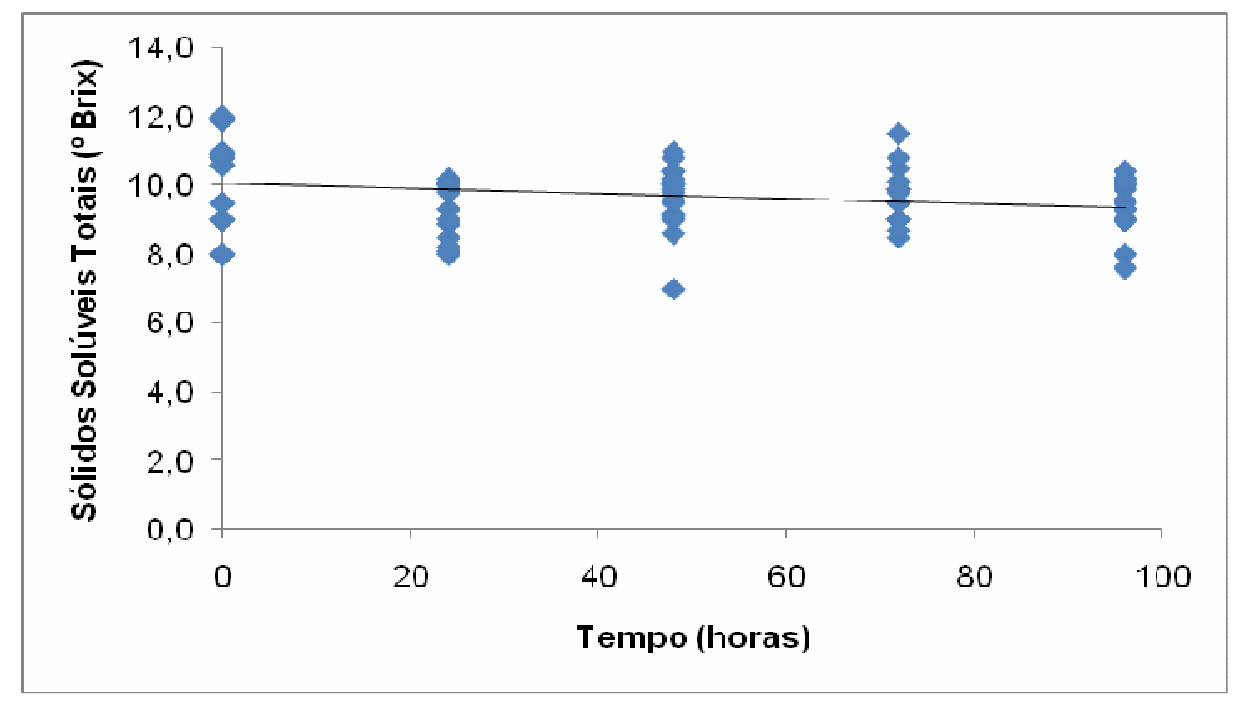

Figura 3: Sólidos solúveis totais ( ${ }^{\circ}$ Brix)) da uva cv. "Rubi" nos diferentes tempos de armazenamento.

Conforme a figura 3, o conteúdo de sólidos solúveis totais da uva diminuiu ao longo do período de armazenamento, em contra partida Detoni et al. (2005), observaram que houve manutenção da doçura em uvas 'Niágara Rosada' armazenadas a $14^{\circ} \mathrm{C}$, por 28 dias. Contrariamente, os mesmos autores constataram perdas na qualidade e na doçura, durante o armazenamento de uvas a $24^{\circ} \mathrm{C}$, por 21 dias, o que demonstra a 
importância do armazenamento em baixas temperaturas na preservação da qualidade das uvas. De acordo com Coombe (1992), citado por Mattiuz et al. (2009), o decréscimo no conteúdo de sólidos solúveis está associado à utilização dos açúcares como substratos na atividade respiratória. Corroborando com os resultados apresentados, Sarzi e Durigan (2002) ao estudarem a manutenção da qualidade durante o armazenamento refrigerado de abacaxi 'pérola' minimamente processado, observaram redução nos teores de sólidos solúveis, de $12 \%$ para $10 \%$.

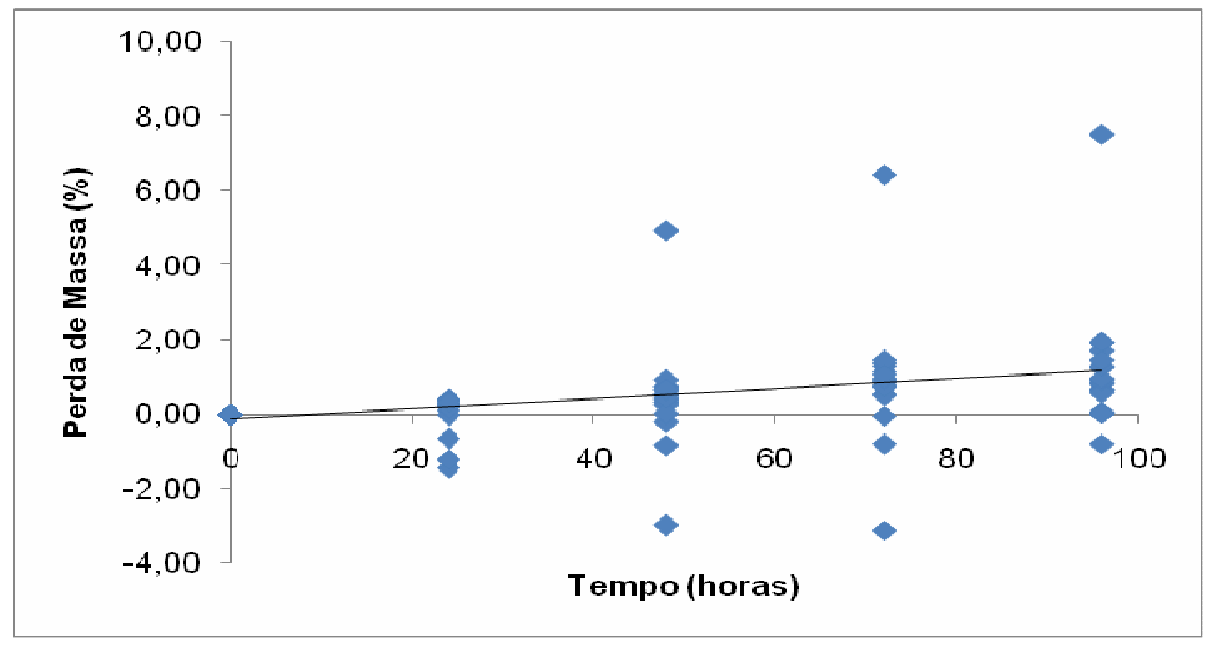

Figura 4:Perda de massa (\%) da uva cv. "Rubi” nos diferentes tempos de armazenamento.

Ao longo do armazenamento, a perda de massa da uva minimamente processada aumentou significativamente $(\mathrm{p}<0,05)$. Nossos resultados estão de acordo com os observados por Groppo (2007). Entretanto, estes valores obtidos, após 96 horas de armazenamento foram inferiores aos citados por Chitarra e Chitarra (2005), que consideram que perdas acima de 5 a $6 \%$ são suficientes para causar o murchamento das bagas.

Somente o conteúdo de cinzas da uva cv. "Rubi" minimamente processada não foi interferido ( $>0,05)$ por nenhuma variável. Alvez et al. (2010) também observaram que o conteúdo de cinzas de produtos minimamente processados não foram afetados significativamente $(p>0,05)$ pelo tempo de armazenamento.

\section{CONCLUSÕES}

Algumas características físico-químicas da uva cv. "Rubi" minimamente processada são alteradas com a aplicação de antioxidantes, tais como sólidos solúveis totais, acidez titulável, umidade, $\mathrm{pH}$, perda de massa e atividade de água. Além disso, a uva cv. "Rubi" apresentou variação no pH e na perda de massa em relação a temperatura de armazenamento, sendo que a menor perda ocorreu à temperatura de $5^{\circ} \mathrm{C}$. Já os conteúdos de perda de massa, sólidos solúveis totais, $\mathrm{pH}$ e atividade de água foram interferidos pelo tempo de armazenamento.

\section{AGRADECIMENTOS}

Ao suporte financeiro oferecido pelo CNPq por meio de bolsa PIBIC para a primeira autora e ao IF SEMG - Campus Rio Pomba pela oportunidade oferecida e suporte para o desenvolvimento deste projeto.

\section{REFERÊNCIAS BIBLIOGRÁFICAS}

ALBERTINI, S.; MIGUEL, A. C. A.; SPOTO, M. H. F. Influência de sanificantes nas características físicas e químicas de uva Itália. Ciência e Tecnologia de Alimentos, Campinas, v.29, n.3, p.504-507, 2009.

ALVES, J. A.; VILAS BOAS, E. V. B.; VILAS BOAS, B. M.; SOUZA, E. C. Qualidade de produto minimamente processado à base de abóbora, cenoura, chuchu e mandioquinha-salsa. Ciência e Tecnologia de Alimentos, Campinas, v.30, n.3, p.625-634, jul.-set., 2010. 
ARAÚJO, J. M. A. Química de Alimentos: teoria e prática. 5 ed., Viçosa-MG, Ed. UFV, 2011. 601p.

BARCELOS, M. F. P.; FERRUA, F. Q. Frutos e hortaliças processados: métodos de conservação e efeitos no valor nutritivo. Textos acadêmicos. Curso de Pós-graduação à distância: Tecnologia e Qualidade de Alimentos Vegetais. Lavras: UFLA/FAEPE, 2003.

BRECHT, J. K.; SALTVEIT, M. E.; TALCOTT, S. T.; MORETTI, C. L. Alterações metabólicas. In: Manual de Processamento Mínimo de Frutas e Hortaliças. Brasília - DF: Embrapa Hortaliças, 2007. $527 \mathrm{p}$.

CARVALHO, A. V. Avaliação da qualidade de kiwis cv. "Haryward", minimamente processados. 2000. 86f. Dissertação (Mestrado em Ciência de Alimentos), Universidade Federal de Lavras, Lavras-MG, 2000.

CARVALHO, A. V.; LIMA, L. C. O. Qualidade de kiwis minimamente processados e submetidos a tratamento com ácido ascórbico, ácido cítrico e cloreto de cálcio. Pesquisa Agropecuária Brasileira v. 37. n. 5, P. 679-685, 2002.

CENCI, S. A. Etapas do processamento mínimo do morango. Comunicado Técnico 110. Rio de Janeiro: Embrapa Agroindústria de Alimentos, 2008.

CHITARRA, M. I. F. Alimentos minimamente processados. Lavras: UFLA/FAEPE, 2001. 93p.

CHITARRA, M. I. F; CHITARRA, A. B. Pós-colheita de frutas e hortaliças: fisiologia e manuseio. 2ed. Lavras: UFLA, 2005. 785p.

DETONI, A. M.; CLEMENTE, E.; BRAGA, G. C.; HERZOG, N. F. Uva 'Niagara Rosada' cultivada no sistema orgânico e armazenada em diferentes temperaturas. Ciência e Tecnologia de Alimentos, Campinas, v.25, n.3, p.546-552, 2005.

FERREIRA, D.F. Programa Sisvar-versão 5.0. Lavras:UFLA, 2007

FREITAS, A. A.; FRANCELIN, M. F.; HIRATA, G. F.; CLEMENTE, E.; SCHMIDT, F. L. Atividades das enzimas peroxidase (POD) e polifenoloxidase (PPO) nas uvas das cultivares benitaka e rubi e em seus sucos e geléias. Ciência e Tecnologia de Alimentos, Campinas, v.28, n.1, p.172-177, 2008.

GOMES, C.; ROSKOSZ, K. A.; SANCHES, M. G.; COSTA, T. A. Conservação de frutas através de embalagens com atmosfera modificada. In: V Semana de Tecnologia em Alimentos, Resumos..., Universidade Tecnológica Federal do Paraná, Ponta Grossa-PR, v.2, n.1, 2007.

GROPPO, V. D. Laranja 'Pêra' (Citrus sinensis L. Osbeck) minimamente processada: efeito de cloreto de cálcio e película de alginato de sódio na fisiologia e conservação. 2007. 98f. Dissertação (Mestrado em Ciência e Tecnologia de Alimentos), Escola Superior de Agricultura Luiz de Queiroz (ESALQ/USP), Piracicaba, 2007.

HEIFFIG, L. S.; AGUILA, J. S.; KLUGE, R. A. Caracterização físico-química e sensorial de frutos de kiwi minimamente processado armazenados sob refrigeração. Revista Iberoamericana de Tecnologia Postcosecha, Hermosillo, México, v.8, n.1, p. 26-32, 2006.

JACOMINO, A. P.; ARRUDA, A. C.; MOREIRA, R. C.; KLUGE, R. A. Processamento mínimo de frutas no Brasil. In: Simposium "Estado actual Del mercado de frutos e vegetales cortados em Iberoamericano". San José, Costa Rica, 2004.

JUNIOR, B. D. Influência de pré-tratamentos químicos nas características físico-químicas e sensoriais do kiwi submetido à desidratação osmótica e armazenado sob refrigeração. 2007. 83f. Dissertação (Mestrado em Tecnologia de Alimentos), Setor de Tecnologia da Universidade Federal do Paraná, Curitiba, 2007.

KLUGE, R. A.; NACHTIGAL, J. C.; FACHINELlO, J. C.; BILHALVA, A. B. Fisiologia e manejo póscolheita de frutas de clima temperado. 2.ed., Pelotas: UFPel, 2002. 216p.

LiMA, A. S., RAMOS, A. L. D., MARCELlini, P. S.; BATISTA, R. A., FARAONI, A. S. Adição de agentes anti-escurecimento, antimicrobiano e utilização de diferentes filmes plásticos, em mamão minimamente processado. Revista Brasileira de Fruticultura, v. 27, n. 1, p. 149-152, 2005. 
MATTIUZ, B.; Miguel, A. C. A.; GAlATI, V. C.; NACHTIGAL, J. C. Efeito da temperatura no armazenamento de uvas apirênicas minimamente processadas. Revista Brasileira de Fruticultura, Jaboticabal - SP, v. 31, n. 1, p. 44-52, 2009.

MATtiuZ, B.; Miguel, A. C. A.; NACHTigAl, J. C.; DURigAN, J. F.; CAMARGO, U. A. Processamento mínimo de uvas de mesa sem semente. Revista Brasileira de Fruticultura, Jaboticabal - SP, v. 26, n. 2, p. 226-229, 2004.

MELO, A. A. M.; VILAS BOAS, E. V. B. Inibição do escurecimento enzimático de banana maçã minimamente processada. Ciência e Tecnologia de Alimentos, v. 26, n. 1, p. 110-115, 2006.

PRADO, M.E.T. ; VILAS BOAS, E.V. de B.; SANTOS, J.C.B.; PINHEIRO, A.C.M.; MATTOS, L.M.; ARAÚJO, F.M.M.; CHITARRA, A.B.; OLIVEIRA, E.C.M. Influência do hipoclorito de sódio sobre a qualidade de abacaxis minimamente processados. In: ENCONTRO NACIONAL DE PROCESSAMENTO MÍNIMO DE FRUTAS E HORTALIÇAS, 2., 2000, Viçosa. Resumos... Viçosa, MG: UFV, 2000. p. 5.

SARZI, B.; DURIGAN, J. F. Avaliação física e química de produtos minimamente processados de abacaxi"Pérola". Revista Brasileira de Fruticultura, v. 24, n. 2, p. 333-337, 2002.

SARZI, B.; DURIGAN, J.F.; ROSSI JÚNIOR, O.D. Temperatura e tipo de preparo na conservação de produto minimamente processado de abacaxi-'pérola'. Revista Brasileira de Fruticultura, v. 24, n. 2, p. 376-380, 2002.

TEIXEIRA, G. H. A.; DURIGAN, J. F.; MATTIUZ, B.; ROSSI JÚNIOR, O. D. Processamento mínimo de mamão 'formosa'. Ciência e Tecnologia de Alimentos, v. 21, n. 1, p. 47-50, jan.-abr. 2001.

VILAS BOAS, E. V. B. Perdas pós-colheita. Lavras: UFLA/FAEPE, 2000. 64p.

ZENEBON, O.; PASCUCT, N.S.; TIGLEA, P. Métodos físico-químicos para análise de alimentos. 4. Ed. São Paulo: Instituto Adolfo Lutz, 2008. 